\title{
Espejismos y una sombra: "La cena" de Alfonso Reyes
}

\author{
María Elena Madrigal Rodríguez \\ Universidad Autónoma Metropolitana, Unidad Azcapotzalco \\ Quien te reconstruya según tus obras, imaginará que \\ pesas cien kilos y que eres una encina de la selva negra \\ Carta de Julio Torri a Alfonso Reyes. México, octubre de 1917.
}

Los dos apenas tenían veintiocho años y Julio Torri estaba cierto de la prodigalidad vital y literaria de su querido amigo Alfonso Reyes. Tal magnitud creativa si bien constituye una fuente de investigación inagotable, también representa un escollo ante cualquier intento abarcador, por lo que los estudios reyistas generalmente se circunscriben a un aspecto, a un corpus o a una pieza. En el caso que me ocupa, "La cena" ofrece la ocasión para atisbar, por una parte, un momento de la vida de su autor y, por la otra, su importancia dentro de la narrativa mexicana puesto que, para algunos críticos, este cuento es paradigmático en la reflexión sobre el surrealismo y el realismo mágico latinoamericanos. Incluso sin ubicarlo en perspectivas mayores, el texto ejemplifica magistralmente la innovación de Alfonso Reyes a partir de su capacidad de síntesis por la imaginación y el intelecto, sus lecturas y su vida.

Un primer paso para valorar "La cena" consiste en partir de 1912, año de su escritura, y perteneciente al "periodo juvenil" de la producción de Reyes (según la atinada apreciación de Julio Torri (1996: 162). En aquel entonces, Reyes se nutría de las lecturas compartidas con los miembros de El Ateneo de la Juventud, mismas que dejarían su huella en la maestría técnica y las alusiones eruditas del texto. Conviene asimismo tomar en cuenta la conmoción revolucionaria del momento para complementar al impelente artístico, sobre todo porque la vorágine política afectó directamente a Reyes. Recordemos que el movimiento armado cumplía dos años de haber estallado y que 
el pueblo empezaba a cansarse de la interminable lucha que se extendía asoladora por todo el país sembrando la ruina; se acusaba al presidente Madero de no cumplir con las promesas de la revolución [...] Emiliano Zapata en el sur continuaba levantado en armas [...] Pascual Orozco en el norte, valiéndose de los elementos que el gobierno le había confiado, se puso en contra de éste y lanzó un manifiesto en que invitaba al pueblo a la sublevación en contra de Madero [...] Victoriano Huerta [...] logró derrotarlo [...] y regresó a la capital [a manifestar pronto] su infame traición. (Arellano: 137-138).

El año de 1912 trajo consigo la sombra del infortunio para Reyes: unos días antes de iniciado, su padre había sido hecho prisionero y trasladado a la cárcel militar de Santiago Tlatelolco y Rodolfo, hermano de Alfonso, era su compañero de celda. Tratemos, pues, de dilucidar "La cena" a la luz de la técnica literaria de factura ateneísta, el arte como motivo para la creación artística y la vida del autor como elemento inseparable de su escritura.

\section{PERfección ESTILÍSTICA}

¡Lástima que el cuentista no haya perseverado en Alfonso Reyes!

Pedro Henríquez Ureña, "Alfonso Reyes”.

En 1927, Pedro Henríquez Ureña se refirió a "La cena” como ejemplo de "creación rotunda y nueva [...] donde los personajes se mueven como fuera de todo plano de gravitación" (297). En efecto; una de las características innovadoras de "La cena" es la propuesta de la esfericidad como elemento constructivo dominante, acorde con una concepción novedosa del tiempo y del espacio. En lugar de tener un principio y un fin, "La cena" se desarrolla a base de espirales y duplicaciones, que trataremos según el orden que tienen en el cuento, hasta donde es posible. Desde el párrafo de apertura, Reyes sitúa a sus lectores en esta nueva dimensión mediante la frase "glorietas circulares", que encuentran su doble en las "redondas esferas de reloj", orientadas hacia "los cuatro vientos". Fundamental para tal efecto son "las nueve campanadas" del inicio en paralelismo con las "nueve sonoras campanadas que estremecían la noche" del 
final. Asimismo, las imágenes de los focos, los relojes y los torreones de esta apertura encontrarán a sus dobles, a su vez, en los "relojes y torreones" que el narrador recuerda poco antes de entrar a la casa de sus anfitrionas y, una vez más, en el cierre del cuento. Los "sembrados arriates" hallan a sus pares en las "placetas sembradas" y en el "jardincillo breve y artificial, como el de un camposanto" hacia la mitad del texto.

Esquemáticamente, el cuento obedece a una construcción por quiasmo, figura retórica representada por la letra $\chi$ (chi) del alfabeto griego, y que posee un par de cualidades que podemos transponer a "La cena". La primera consiste en que, infinitamente, la $\chi$ puede ser replicada en cadenas lineales o entrecruzada para dar la impresión de volumen. La segunda, en que la $\chi$ está formada por desdoblamiento —o duplicación - de cada uno de los cuatro segmentos de recta que la forman. Es así que sobre el recuerdo de haber estado en una circunstancia parecida (párrafo segundo), el narrador habla de "aquella falsa recordación" en el tercero, luego rememora haber recibido la nota de invitación y más adelante - otra vez antes de entrar en la casa - nos dice que evoca, en sus pesadillas "aquella noche fantástica".

Pero no sólo a los escenarios y a la acción de recordar Reyes elabora sus contrapartes, sino a los objetos, que cobran así una relevancia simbólica fundamental. Es indispensable mencionar a dos de ellos, en primer lugar a la "esquela breve y sugestiva". La nota representa un llamado, por la escritura, hacia el mundo de los sueños y sus misterios, cuyo doble aparece hacia el final, cuando Amalia pronuncia la frase " $i L e$ hará tanto bien!", en referencia al capitán, que no al narrador, y es entonces cuando se completa el sentido de la invitación, expresado en una oración parentética: “(«i Ah, si no faltara!» [...] «iLe hará tanto bien!»)". La imagen se prolonga, por la escritura, en la idéntica caligrafía de la invitación y la de la dedicatoria del retrato del capitán. El segundo objeto capital es la naturaleza, que se nos presenta como un acertijo de connotaciones filosóficas y poéticas en la frase referida a las "cosas cotidianas y cuyo equívoco misterio crece sobre la humilde raíz de lo posible". La imagen vegetal abre la vía al jardín, donde el protagonista será rodeado por las "flores que muerden y [las] flores que besan; [por los] tallos que se arrancan a su raíz y os trepan, como serpientes, hasta el cuello". La indefensión de Alfonso ante el encanto y poder de lo sobrenatural nos es confirmada cuando dice: "A mis pies se habían enredado las guías vegetales del jardín; había hojas sobre mi cabeza”. Las hojas 
reaparecen junto al símbolo culminante de "La cena": la "florecilla modesta", de presencia ajena a la voluntad de Alfonso, y cuyo adjetivo se equilibra, en perfecta sinonimia, con la humildad de la "raíz de lo posible".

A continuación de los lugares, las acciones y los objetos, Reyes incorpora a los pares ontológicos, es decir, a los seres o personajes que pueblan el texto. Los desdoblamientos tienen lugar en cuanto a sus sustancias, medios de expresión, reacciones corporales, apariencias y, sobre todo, nombres. Gracias a "un cuadro de luz", el primer encuentro no se da ante presencias físicas sino entre las sombras de doña Magdalena y de Alfonso que hallan su alteridad en "las sombras desteñidas de las dos mujeres" a la luz de una "lámpara de dos luces", con lo que la luz y los seres y sus sombras quedan en armonía y contraposición. Alfonso, el personaje, está ahora a la puerta de la casa de sus anfitrionas y aún no ha perdido el control de sí mismo, puesto que por la vista y la imaginación recrea posibilidades para la fisonomía de Amalia, por la palabra intenta fórmulas de cortesía social y, por el oído, escucha su nombre. ${ }^{1}$ La lucidez del protagonista queda también manifiesta porque Amalia y Alfonso no necesitan presentarse entre sí, sino que se reconocen mutuamente, por una misteriosa correspondencia entre nombre y ser, mediante la frase "todo aquel ser me pareció plegarse y formarse a las sugestiones de un nombre" y al indicar que la voz de Amalia bien pudiera ser un duplicado de la suya.

El uso de la palabra cede ante formas de entendimiento más sutiles entre los personajes, que comienzan a valerse de una alternancia de suspiros, de "miradas paralelas" entre los varones (Alfonso y el retrato que lleva dońa Magdalena al pecho) o entre las dos mujeres, además de la interpretación de los semblantes de estas últimas (sucesivamente de piedad, satisfacción, angustia, inquietud y finalmente desahogo). A los cambios fisiológicos de las mujeres corresponden las transformaciones físicas de Alfonso quien, al beber el Chablis ${ }^{2}$ sufre una alteración de los sentidos

${ }^{1}$ Llegados a este punto, nos hallamos con que el nombre del protagonista es homónimo del autor, táctica del Doppelgänger, a la que han recurrido incontables artistas de todos los tiempos y que asimismo ha sido motivo para los críticos de arte. Entre estos últimos, y en concordancia con una de las escuelas decisivas en la formación de Reyes, podemos señalar a Walter Pater quien estudia al Doppelgänger, en función de Amis et Amile (Pater: 11).

${ }^{2}$ La elección de la bebida no es casual, puesto que Reyes bien sabía de la fama de este vino blanco, espirituoso, perfumado y límpido, popular desde los tiempos de Napo- 
y entonces se guía más por la adivinación y la imaginación. Este estado deja la puerta abierta a las contradicciones en sus apreciaciones, como cuando, por un lado, dice sentirse a su gusto "como en casa de alguna tía viuda y junto a alguna prima” y, por el otro, habla de la conversación apropiada para aquellas casas "donde no somos de confianza"; o cuando dice haber tenido "pleno conocimiento de [su] estado" para acto seguido "confundir sus palabras [las de las mujeres] con mi fantasía".

Para concluir este apartado, volvamos al esquema quiásmico, en el que notamos un punto de intersección al centro de la $\chi$, donde las operaciones combinatorias posibles se encuentran, aunque sea de manera provisoria. En "La cena”, el punto de coincidencia corresponde al retrato del capitán, simultáneamente locus, objeto, actuar y ser, puesto que se nos deja entrever que él envió la nota; porque hay una identidad física exacta entre él y Alfonso; porque es un muerto dispuesto a escuchar así como a vivir un deseo no realizado por medio de la palabra de un Alfonso vivo; porque es un ciego, que paradójicamente estuvo "bajo el Arco de la Estrella”, símbolo de la luminosidad, "adivinándolo todo a su alrededor", cual le sucedió a Alfonso, que adivinó el jardín (el verbo se repite dos veces: "pude adivinar", "yo adivinaba”), porque no veía nada a causa de la oscuridad y su somnolencia.

EL ARTE

Entrada es ya la noche. Palpita con zozobra debajo la tetera la llama de alcohol.

El alma de los libros despierta y se recobra.

Es la hora en que, a diario, para seguir la obra, enciéndese la lámpara al apagarse el sol.

Alfonso Reyes, "Lluvias de julio”, México, 1912.

Los desdoblamientos o juegos especulares de "La cena" son también piedra angular de una obra de Stevenson (autor que Reyes tenía presente por 1912) y que pasados los ańos no ha perdido su fascinación: Dr. Jekyll

león III y al que se le atribuye la intensificación de la lucidez y la inteligencia. En Minuta y en Memorias de cocina, Reyes dejó otras constancias de su gusto por lo culinario (de sus Obras completas, véanse el vol. X, 363-384 y el vol. XXV, respectivamente). 
and Mr. Hide. Además de la alusión a Stevenson, hay por lo menos otras cuatro referencias veladas en "La cena". La primera es a Chesterton -el segundo autor que en ese momento ocupaba a Reyes y al que tradujo- 3 cuya huella detectivesca se deja ver en el encadenamiento de enigmas que el protagonista (y el lector junto con él) ha de resolver por pistas a lo largo del cuento. La segunda es a Amado Nervo, ${ }^{4}$ quien al narrar un viaje por las densidades del yo interno en "El castillo de lo inconsciente" inicia la corriente fantástica en nuestro país, que alcanzará su primera etapa de esplendor con tres ateneístas: Alfonso Reyes y Martín Luis Guzmán, en sus primeras épocas, y Julio Torri.

La tercera alusión críptica corresponde al tratamiento estereotipado de plantas y flores por parte de artistas del decadentismo europeo. El crítico Mario Praz abunda en ejemplos donde flores y plantas de formas equívocas y extrañas son inseparables de situaciones de tortura, horror, muerte y lujuria que, en "La cena", son reveladas a los lectores entendidos en la literatura y la pintura decadentistas. ${ }^{5}$

La cuarta referencia velada, y tal vez la de mayor peso en "La cena", es un apunte de Samuel Taylor Coleridge, de quien Alfonso Reyes partió para lograr el horror de transgredir los planos onírico y "real" mediante la superposición de las dimensiones temporales y espaciales, las identidades de los personajes, y las naturalezas y los símbolos de los objetos. La alusión a Coleridge ha sido señalada por James Willis Robb (118), ${ }^{6}$ uno de los críticos más acuciosos de Reyes, pero conviene abundar en ella. Se trata de unas líneas aisladas donde se lee: "If a man could pass thro'

3 "De la ortodoxia de Chesterton", bajo petición de Rafael Calleja, a través de Juan Ramón Jiménez.

${ }^{4}$ La admiración que profesaba Alfonso Reyes por el bardo nayarita se manifestó de manera concreta en la edición que dirigió de las Obras completas de Amado Nervo (en 28 volúmenes) para la Biblioteca Nueva, de Madrid (Torri 1996: 169).

${ }^{5}$ En este sentido, Mario Praz hace un detenido análisis de Huysmans, Moreau, Mirabeau y los prerrafaelistas, por ejemplo (309-349). En términos amplios, las flores sugerían la paradoja de los elementos que, perteneciendo a la naturaleza, actuaban contra natura. Como también lo señala Praz, las flores constituían la imagen algolágnica en la poesía de D'Annunzio (50); eran utilizadas como medio de la decapitación por brujería (349 y 406); hacían las veces de veneno (409 y 443) o bien —en particular la orquídea y el loto- simbolizaban la homosexualidad masculina (294).

${ }^{6}$ Asimismo, Robb menciona la conexión que Borges establece entre la flor de Coleridge y la de $\mathrm{H}$. G. Wells, que comento más adelante. 
Paradise in a Dream, \& have a flower presented to him as a pledge that his Soul had really been there, $\&$ found that flower in his hand when he awoke -Aye? And what then?” (Coleridge: 127, entrada 536). En otras instancias dentro del mismo cuaderno de notas (la entrada 281, por ejemplo) o en el famoso poema "Kubla Khan", Coleridge recurre a símbolos y al oneirismo para inducir al lector a un estado liminal entre la vigilia y el sueño, pletórico de entresijos, como los que él experimentaba en el consumo de opio, pero que Reyes aprovecha para lograr un nuevo equilibrio entre la racionalidad y la irracionalidad.

En su momento, la alusión de Reyes a la nota de Coleridge formaba parte de un código que sólo los pocos entendidos en literatura inglesa descubrían, a diferencia de épocas más recientes, en que se debe a Borges su difusión en el mundo hispánico. En efecto, en el ensayo "La flor de Coleridge" Borges ofrece tal vez la primera traducción del pasaje: "Si un hombre atravesara el Paraíso en un sueño, y le dieran una flor como prueba de que había estado allí, y si al despertar encontrara esa flor en su mano [...] entonces, ¿qué?” (22) y el comentario que agrega resulta decisivo para entender un viso de "La cena". Dice Borges: "detrás de la invención de Coleridge está la general y antigua invención de las generaciones de amantes que pidieron como prenda una flor" (22). En otras palabras, la flor se convierte en "la prueba", en el objeto material que da fe, paradójicamente, de la existencia de la subjetividad, de lo inconmensurable, de los sentimientos. Por la literatura es que Alfonso Reyes critica a la filosofía positivista, con su dogmatismo y apego ciego a la lógica y al rigor del método, y deja saber de su afiliación a dos escritores capitales: Charles Baudelaire y Joris Karl Huysmans, autores de Les fleurs du mal y de $A$ rebours, respectivamente, obras donde una naturaleza maligna y misteriosa funge cual antídoto simbólico al formalismo y al naturalismo mediante el cultivo de la imaginación.

Dentro de este sistema de eliminación de fronteras entre imaginación y realidad encuentran su sitio las referencias artísticas explícitas: san Juan de la Cruz, Sudermann, Ibsen y Echave el Viejo. ${ }^{7}$ La de san Juan de la

${ }^{7}$ Baltasar de Echave Orio fue un pintor vascongado asentado en la Nueva España hacia 1560, donde se casó y trabajó por unos treinta ańos. Se le conoce una veintena de obras. Un ejemplo de los contrastes de su pintura es el conjunto La Anunciación, la Adoración de los Reyes y la Visitación, donde "hay zonas luminosas donde destacan los colores vivos" (Victoria: 113). 
Cruz, en el epígrafe, constituye el primer enigma para el lector, puesto que proviene del "Cántico", ${ }^{8}$ composición aurisecular que trata del tránsito del alma al estado de perfección y en la lectura de "La cena" no hallamos referencia alguna a ese tema. Nuevamente, Reyes exige una reflexión detenida para hallar la clave. El fraile carmelita explica en su Anotación al "Cántico" que "Este nombre cena se entiende por visión divina (Ap. 3, 20)". ${ }^{9}$ Es decir, debemos situarnos en el uso de la cena como símbolo por parte de san Juan de la Cruz así como en su estilo en tanto su medio para explicar con palabras la experiencia mística del éxtasis. En tan difícil tarea compositiva, hay cabida para el trastrocamiento de la lógica, las escenas oníricas y un afán por disolver el espacio y el tiempo; incluso hay pérdidas de identidad debidas a la fusión de un ser con otro (al igual que en "La cena"), como cuando la Esposa se mira en una fuente y se encuentra, para su sorpresa, no con su reflejo sino con los ojos de su Amado. Al "Cántico", explica Luce López-Baralt en su Prólogo a la Obra completa de San Juan de la Cruz, rige una "Poética del delirio [tipificada por un] fragmentarismo borroso que nunca acabamos de comprender: los cambios abruptos de espacio; la incongruencia de los tiempos verbales y los desplazamientos temporales injustificados; las imágenes desconcertantes" (I, 35). Sorprende, entonces, la manera sintética y delicada por la que Reyes hace un llamado al lector entendido en temas literarios, como si se tratara de reconocer el nombre y las cualidades de un perfume con tan sólo percibir un dejo de la esencia.

Las otras tres referencias explícitas refuerzan, entre sí, las ideas de lo externo y de la vida social, encarnadas por doña Magdalena y por Amalia. En un extremo del triángulo referencial está Hermann Sudermann (1857-1928), escritor paradigmático del movimiento realista alemán, sobresaliente por su agudo sentido de la observación, al que quedaban supeditadas la belleza y la fuerza de las emociones; en el otro, el noruego Henrik Ibsen (1828-1906), que con tono satírico y actitud inmisericorde criticó la hipocresía, el deshonor y la avaricia utilizando las relaciones familiares como analogías microcósmicas de la sociedad. Completa

${ }^{8}$ Específicamente, el verso pertenece a la Canción 14 en la composición primitiva (San Juan de la Cruz 1, 61), y a la 15 en la segunda, que es una reorganización de la primera $(2,16)$. La redacción del "Cántico" inició en Toledo entre los años 1577 y 1578 y culminó en Granada en 1584.

${ }^{9}$ Anotación 8 a la canción XV $(2,101)$. 
la tercia Echave el Viejo, pintor que lograba altas notas de teatralidad, como se indica en "La cena", con los contrastes de claroscurismo. En su conjunto, las alusiones permiten a Reyes construir a estos personajes femeninos según estereotipos de superficialidad y fingimiento, aunados a la frialdad propia de los estereotipos decadentistas.

LA VIDA

Canción es autobiografía; la suya toda en símbolo y cifra. Pedro Henríquez Ureña, "Alfonso Reyes".

Hace tiempo, James Willis Robb señaló los pasajes en que Alfonso Reyes admitió tres elementos biográficos de "La cena": una pesadilla, una conversación en la que Jesús T. Acevedo le contó las impresiones extravagantes que le dejó la visita a una familia desconocida y su inventiva (17). A ellos, Robb añade que el capitán del retrato pudiera corresponder al general Bernardo Reyes, puesto que estuvo un tiempo en París y perdió la visión de un ojo. Dada la plausibilidad de esta conjetura, y del peso simbólico que la figura posee en "La cena", conviene abundar en la cuestión y hacer algunas puntualizaciones.

El declinar de uno de los hombres más poderosos y carismáticos del porfiriato inició en noviembre de 1909, cuando salió a París, enviado por Díaz, a fin de que no interfiriera en los planes de reelección del dictador, pero don Bernardo Reyes consideró la encomienda como parte de su trabajo al servicio de México: "Durante el tiempo que permaneció alejado de su patria el divisionario jalisciense no cejó en sus estudios acerca del ejército y también en París escribió un pequeño trabajo para informar sobre el servicio de aguas y drenaje que fue una de las últimas obras inauguradas en su gobierno [del estado de Nuevo León]”. En otras palabras, su estancia en París no fue de placer; no pudo mirar "la ciudad luz" como un sitio pletórico de arte y belleza. Asimismo, en ese viaje, "en una ocasión en que [...] presenciaba unas maniobras militares [...] sintió una ligera molestia visual que descuidó en atenderse debidamente, la que originó una hemorragia y la pérdida total de la vista en un ojo, lo que sólo su esposa conoció, y sería tiempo más tarde cuando sus hijos lo sabrían" (Arellano: 71). 
Indica Robb que el general Bernardo Reyes había sido preso en 1912, pero en realidad fue unos días antes: el 28 de diciembre de 1911 acusado de conspiración contra el gobierno de Madero (Arellano: 135). No es difícil imaginar el dolor de los suyos, sobre todo cuando fue trasladado al Hospital Militar a causa del paludismo y de nuevo a la prisión, o cuando leyeron la Defensa que por si mismo produce el C. General de División Bernardo Reyes acusado de delito de rebelión (México, Imprenta Lacaud, 1912). Desde un año antes el joven Alfonso presentía el acecho de la desgracia y aunque en lo cotidiano y amistoso la vida se desenvolvía liviana, en el fondo de sí hacían mella el espanto de la muerte y la barbarie. ${ }^{10}$ Por todo esto, resulta un tanto comprensible la identificación del narrador de "La cena" con la muerte, con el deseo de haber disfrutado París o de haberlo conocido por la voz de un poeta y con el deseo del hijo por cargar sobre sí con el infortunio del padre.

Con fundamento en Borges, Robb indica que el retrato como objeto en el que se cruzan las identidades del narrador y del capitán tiene su referente en Henry James, quien "dejó inconclusa una novela de carácter fantástico, The sense of the past [... donde] el nexo entre lo real y lo imaginativo (entre la actualidad y el pasado) no es una flor [... sino] un retrato que data del siglo XviII y que misteriosamente representa al protagonista" (Borges: 24-25). Sin embargo, el posible vínculo que establece Robb entre Reyes y James sería en el sentido opuesto: The sense of the past fue escrita años después que la "La cena", y fue dada a conocer póstumamente. La experiencia de vida que posiblemente subyace a la imagen del capitán en el pecho de doña Magdalena tiene que ver con la postulación del general Bernardo Reyes para la vicepresidencia (y Porfirio Díaz para la reelección), y la decisión de "los socios [del Club Central Reyista por] portar como distintivo un retrato de su candidato", según un acuerdo tomado el 22 de mayo de 1909 (Arellano: 93).

Un par de visos biográficos más nos ayudan a completar este rubro: una de las hermanas de Alfonso Reyes se llamaba Amalia; Alfonso, cuando niño, había experimentado el misterio de perderse dentro de sí mismo. Alguna vez le contó a Emmanuel Carballo lo siguiente:

${ }^{10}$ En una carta fechada el 6 de mayo de 1911, a Pedro Henríquez Ureña, Alfonso Reyes confiesa sus temores. Al respecto, véanse Alfonso Reyes y Pedro Henríquez Ureña (169) y Alfonso García Morales (192-194). 
Estimulado por la fiebre que frecuentemente padecía - y acaso era una fiebre palúdica - caía en delirios, como solíamos llamarlos, que generalmente eran visuales. Pero, aficionado como era a quedarme solo, yo me deslizaba, de la manera más natural, sin saber por cuáles caminos, a un estado de olvido y abstracción que me hacía perder del todo la conciencia de mi ser limitado. De pronto me recobraba. Entonces me sentía como espantado. El caer del éxtasis me asustaba, como en Plotino. Ser yo mismo, ser una cosa sujeta en un alma y en un cuerpo particulares, me causaba verdadero pavor. Corría yo a verme en el espejo para mejor lograr mi descenso desde el cielo a la tierra; corría a buscar a alguien que me hablara, que me ayudara otra vez a anudar mis lazos. Con la infancia desapareció este don envidiable (1965: 100-101).

\section{PoÉtica DE LA CONCILIACIÓN}

Como artista, [Alfonso sabía] que las antinomias del universo se resuelven, para el sentido espectacular, en armonías.

Pedro Henríquez Ureña, "Alfonso Reyes".

El ahondamiento en ciertas cualidades de "La cena" representa una oportunidad para reflexionar sobre las marcas distintivas de la obra temprana de Alfonso Reyes. Una de ellas es el recurrir a la literatura o al arte como abrevadero para la inspiración, actitud compartida por sus amigos ateneístas más cercanos, con quienes parece continuar conversando mediante las referencias veladas y explícitas a los temas culturales que los ocupaban.

Otra propensión literaria que Reyes no abandonaría, es la de la búsqueda del equilibrio y la perfección en el estilo, como agudamente lo percibió Pedro Henríquez Ureña. En el caso de "La cena" la armonía se traduce en la confluencia entre las figuras del protagonista, del testigo y vocero del relato así como de los símbolos de la autoridad, el deseo y la muerte (el "Alfonso" personaje, el "Alfonso autor" y el hombre del retrato). Reyes encuentra el justo medio entre lo sobrenatural y la lucidez epistemológica. En un momento en que muchos jóvenes intentaron dar la espalda a la herencia positivista mediante el hundimiento en las oscuridades de la subjetividad, Henríquez Ureńa nos recuerda que Reyes "resistió $[\ldots]$ a la fascinación del irracionalismo. El impulso y el instinto, 
en él, [llamaron] a la razón" (298) como elemento orquestador de la experiencia.

Cuando el protagonista narra el contacto con el mundo de los sueńos - con sus sombras y sus juegos especulares - a manera de un recuerdo deja abierta la posibilidad de convivencia de distintos universos, cada uno obediente a sus propias leyes. La maestría para crear por la escritura los entretejidos de luz y oscuridad, de vigilia y sueño, de lo femenino y lo masculino, del jardín y la flor como naturaleza y del escenario callejero y el comedor como artificialidad, por mencionar algunos, manifiestan la conciliación entre el afán de perfección de los ateneístas y el desafío de dar cuenta del mundo onírico donde se irrumpen las reglas del lenguaje.

Se diría, además, que a "La cena" de Reyes han sido convidadas figuras tutelares como Amado Nervo pero también contemporáneos de otros tiempos y lugares. En ella tienen sitio un novelista alemán, un dramaturgo noruego o el novohispano Baltasar de Echave Orio, quien sería el emblema del ideal ateneísta de buscar en toda manifestación artística los medios para lograr el efecto de belleza. El texto de Reyes da superlativa cuenta de la traslación de la técnica lumínica de Echave a un texto donde la luz y sus matices son fundamentales para el logro de la atmósfera inmaterial. Asimismo, la mención a Echave, artista conocido en círculos restringidos, forma parte de otro ideal del Ateneo: revalorar la cultura nacida en México, con hincapié en el colonialismo, periodo al que se dedicaron los jóvenes Jesús T. Acevedo y Genaro Estrada. En el plano de las ideas, el elemento helenista es la clave de "La cena", puesto que en la cultura griega los temas del sueńo, el alma o los mundos divinos paralelos al humano formaban parte de la reflexión y el arte. En el caso que nos ocupa, unos versos del Ayax de Sófocles bien condensan motivo e intención de "La cena":

Pues veo que nosotros, los vivientes, no somos más que espejismos y una sombra efímera.

(Schopenhauer, I. 5. 65). ${ }^{11}$

${ }^{11}$ En este apartado, Schopenhauer discurre larga y poéticamente sobre la vida onírica del ser humano y se apoya en la literatura para sustentar sus argumentos. Schopenhauer fue una de las lecturas predilectas de Reyes, Henríquez Ureña, Torri y el filósofo Antonio Caso. 
"La cena" también es punto de conciliación con el futuro. Julio Torri consideraba que:

Alfonso fue un autor que deslumbraba al lector con la pirotecnia de su inteligencia siempre alerta y activa: con las innumerables referencias a toda suerte de lecturas; con la avalancha de sus oportunas citas. En el mundo de las ideas descubre relaciones nuevas e insospechadas, sin fatiga y en un juego que tiene mucho del arte del prestidigitador (Torri 166).

Todas estas cualidades han hecho de Reyes un modelo de escritura, atractivo para críticos, traductores y creadores por igual. Rick Francis, uno de sus primeros traductores al inglés, en una conversación con Ilan Stavans expresaba sus apreciaciones sobre la incidencia de "La cena" en la literatura mexicana posterior; decía Francis: "As I read the story, it evoked me the dreamy tone of Juan Rulfo's Pedro Páramo, and of Carlos Fuentes' Aura, with which it shares a number of similarities of plot and structure" (Stavans: 3). ${ }^{12}$ El crítico Emmanuel Carballo atribuye a Alfonso Reyes y a Julio Torri la paternidad de la corriente imaginativa del cuento mexicano contemporáneo (87) e inclusive se ha dicho que "La cena" prefigura vetas de la literatura vanguardista en Europa.

"La cena" finalmente salió a publicación en Madrid, en 1920, dentro de El plano oblicuo, exquisito libro de la literatura mexicana, testimonio del por qué Alfonso Reyes sigue siendo encina de magnífica sombra.

12 Gerald Petersen trata las coincidencias temáticas y formales entre "La cena" y Aura, aunque su artículo es meramente descriptivo. 
BIBLIOGRAFÍA

Arellano, Josefina G. De. Bernardo Reyes y el movimiento reyista en México. México: Instituto Nacional de Antropología e Historia, 1982.

Borges, Jorge Luis. "La flor de Coleridge", en Otras inquisiciones. Buenos Aires: Emecé, 1999.

Carballo, Emmanuel. Protagonistas de la literatura mexicana. México: Porrúa, 1965.

Coleridge, Samuel Taylor. Coleridge's notebooks. A selection. Seamus Perry (ed.). Oxford: Oxford University Press, 2002.

Curiel, Fernando. La revuelta. Interpretación del Ateneo de la Juventud (19061929), México: Universidad Nacional Autónoma de México, 1998.

García Morales, Alfonso. El Ateneo de México, 1906-1914. Orígenes de la cultura mexicana contemporánea. Sevilla: Escuela de Estudios HispanoAmericanos de Sevilla, 1992.

Henríquez Ureña, Pedro. "Alfonso Reyes", en Obra crítica. México: Fondo de Cultura Económica, 1980.

Juan de la Cruz, San. San Juan de la Cruz: Obra completa. I, II. Luce LópezBaralt y Eulogio Pacho (eds.). Madrid: Alianza Editorial, 1991.

Nervo, Amado. "El castillo de lo inconsciente", en Cuentos y crónicas. México: Universidad Nacional Autónoma de México, 1993.

Pater, Walter. The Renaissance. Studies in art and poetry. [Primera edición 1893]. New York: Dover, 2005.

Petersen, Gerald. "A literary parallel: 'La cena' by Alfonso Reyes and Aura by Carlos Fuentes”, en Más páginas sobre Alfonso Reyes, vol. III, segunda parte. Prólogo y compilación de James Willis Robb. México: El Colegio Nacional, 1996. 760-764.

Praz, Mario. The romantic agony. Translated by Angus Davidson. 2nd edition and impression, 1954. London: Oxford University Press, 1933.

Reyes, Alfonso. "La cena". Obras completas de Alfonso Reyes, III. México: Fondo de Cultura Económica, 1995.

—_. "Juana", en Obras completas de Alfonso Reyes, X. México: Fondo de Cultura Económica, 1996.

— y Pedro Henríquez Ureña. Correspondencia I, 1907-1914. José Luis Martínez (ed.). México: Fondo de Cultura Económica, 1986.

Robb, James Willis. “'La cena’ de Alfonso Reyes, cuento onírico: ¿surrealismo o realismo mágico?” De la crónica a la nueva narrativa mexicana. Coloquio sobre literatura mexicana. Merlin H. Forster y Julio Ortega (eds.). México: Oasis, 1986. 
Schopenhauer, Arthur. El mundo como voluntad y representación I. Traducción, Introducción y notas de Pilar López de Santa María. Madrid: Trotta, 2004. Stanton, Anthony. "Poesía y poética en Alfonso Reyes", en Inventores de tradición: ensayos sobre poesía mexicana moderna. México: El Colegio de México / Fondo de Cultura Económica, 1998.

Stavans, Ilan (ed.). Prospero's mirror. A translator's portfolio of Latin American short fiction. Willimantic, CT: Curbstone Press, 1998.

Torri, Julio. "Notas sobre Alfonso Reyes", en Tres libros. [Segunda reimpresión]. México: Fondo de Cultura Económica, 1996.

—. Carta de Julio Torri a Alfonso Reyes, México, octubre de 1917, en Epistolarios. Serge I. Zaïtzeff (ed.). México: Universidad Nacional Autónoma de México, 1995.

Victoria, José Guadalupe. Un pintor en su tiempo: Baltasar de Echave Orio. México: Universidad Nacional Autónoma de México, Instituto de Investigaciones Estéticas, 1994. 